kathken litgerald for collecting the data reported here.

2. The author wishes to express appreciation to Dr. Robert L. Henley. A ssistant Superintendent of Teaching Personnel of the Mehlville R-9 School District and to the principal and teachers of Bierbaum School, Mehlville, Mo., for making this study possible.

3. Duc to scheduling problems and pupil absences, some Ss were tested within 1 week of 6 months from their first experimental session. For the same reasons, a few $S$ s were tested 1 day belore or after they should have been given their 1-weck test.

\title{
Probability matching in signal detection
}

\author{
DONALD D. DORFMAN, University of \\ lowa. Lowa City, Iowa 52240
}

There is evidence that in a signal-detection task, Ss often report a stimulus event at about the probability of its occurrence. By contrast, it has often been assumed in signal detection theory that $S$ s attempt to maximize expected value. Green (1960) and Green \& Swets (1966) have presented a rather detailed analysis of the data of one particular $O$, whom they have characterized as typical. They concluded that $O s$ tend to avoid extreme criteria, and may be described as conservative. $A$ reanalysis of their results shows that the $S$ was matching his probability of a "yes" response to the probability of the signal.

There is a fair amount of evidence that in a signal-detection task, Ss of ten report a stimulus event at about the probability of its occurrence (e.g., Atkinson \& Kinchla, 1965; Creelman \& Donaldson, 1968; Parks \& Kellicutt. 1968). By contrast, it has often been assumed in signal-detection theory (e.g., Swets, Tanner, \& Birdsall, 1961; Green, 1960; Green \& Swets, 1966) that Ss attempt to maximize expected value. Specifically, it is assumed that the $S$ sets a criterion on some monotone transformation of the likelihood ratio axis, usually attempting to maximize expected value. Green (1960) and Green \& Swets (1965) have presented a somewhat detailed analysis of the data of one particular $\mathrm{O}$, whom they have characterized as typical. On the basis of a comparison of the ubtained Beta (B) with the optimal B, they concluded that Ss tend to avoid extreme criteria, and may be described as more conservative than the optimal S. They conclude that "when B is relatively large, his actual criterion is not so high as the optimal criterion, and when the optimal criterion is relatively small, his criterion is not so low as the optimal criterion [Green \& Swets, 1966, p. 91]." They present some reasons why such should be the case. First, they state that the $S$ is disinclined to make the same response on all trials. Secondly, they point out that the expected value function is quite flat for a wide range about its maximum, and that consequently, conservative criteria would have a small effect upon the percentage of correct responses. An al ternative hypothesis is that the $S$ was probability matching. Green \& Swets (1966) did not investigate this hypothesis.

Figure 1 presents the data of this $S$ plotted in a particular way. The figure presents the probability of a "yes" response plotted against the probability of a signal (S). If probability matching occurred, all of the data points would fall on the positive diagonal. It is clear that the deviations from probability matching are quite small. Table 1 presents the obtained probability of a "yes" response and the associated probability of a signal. For purposes of

\begin{tabular}{cc} 
& Table 1 \\
\hline $\mathrm{P}(\mathrm{S})$ & $\mathrm{P}(\mathrm{Y}$ (s) $)$ \\
\hline .1 & .1145 \\
.3 & .2965 \\
.5 & .5575 \\
.7 & .6965 \\
9 & .9015 \\
\hline
\end{tabular}

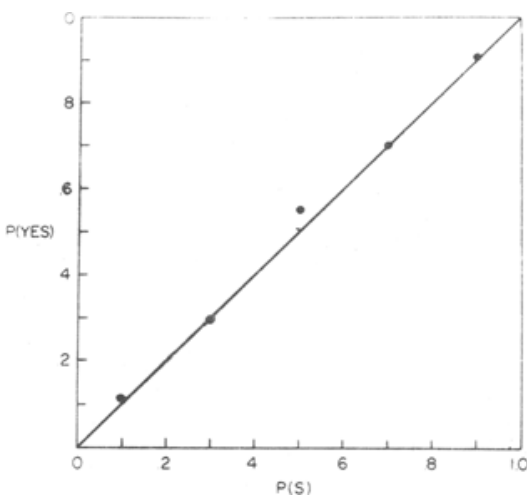

Fig. 1. Probability of a "yes" response as a function of the probability of the signal.

statistical testing, assume that the Null Hypothesis is that $P(Y e s)=P(S)$, that we are dealing with five independent tests of the hypothesis, and that there is binomial variability. Given these assumptions, a 95\% simultaneous confidence interval can be obtained (Hays, 1963, pp. 312-314). Given this confidence interval, all of the observed proportions are within the range of random variability. Consequently, the hypothesis of probability matching was supported. This hypothesis has a substantial advantage over some of the hypotheses proposed by Green \& Swets (1966) since it makes exact numerical predictions. Also, it has a reasonable basis in that it is an asymptotic theorem of some learning models (e.g., 'uce, 1963; Atkinson \& Kinchla, 1965). 2

\section{REFERENCES}

ATKINSON, R. C., \& KINCHLA, R. A. A learning model for forced-choice detection experiments. British Journal of Mathematical \& Statistical Psychology, 1965, 18, 183-206.

CREELMAN, C. D., \& DONALDSON, W. ROC curves for discrimination of linear extent. Journal of Experimental Psychology, 1968,77, 514-516.

GREEN, D. M. Psychoacoustics and detection theory. Journal of the Acoustical Society of America, 1960, 32, 1189-1203.

GREEN, D. M., \& SWETS, J. A. Signal detection theory and psychophysics. New York: Wiley, 1966.

HAYS, W. L. Statistics for psychologists. New York: Holt, 1963.

LUCE, R. D. A threshold theory for simple detection experiments. Psychological Review, $1963,70,61.79$.

PARKS, T. E., \& KELliCUT, M. H. The probability-matching rule in the visual discrimination of order. Perception \& Psychophysics, 1968, 3, 356-360.

SWETS, J. A., TANNER, W. P., JR., \& BIRDSALL, T. G. Decision processes in perception. Psychological Review, 1961, 68, 301-340.

\section{NOTES}

1. Supported in part by NSF-GS- 1466 .

2. McGill, W. J. Poisson counting and detection in sensory systems. Unpublished manuscript, Department of Psychology, University of California. San Diego. February 10. 1966. 